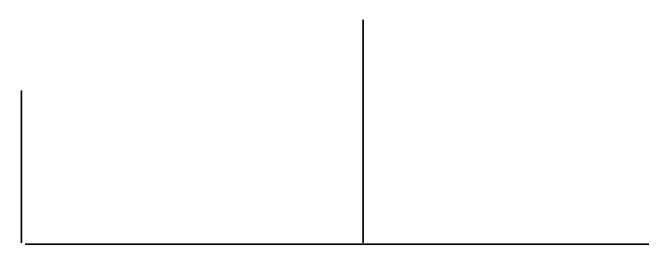

Rev. Latinoam. Psicopat. Fund., VI, 4, 102-116

\title{
Trauma e temporalidade
}

Ana Maria Rudge

\begin{abstract}
O trauma tem sido abordado na literatura psicanalítica especialmente como um trauma infantil de natureza sexual. A neurose traumática é tomada como modelo para a circunscrição de uma acepção de trauma que não se confunde com o trauma estrutural eficaz na constituição do psiquismo, e cuja sintomatologia não pode ser diretamente remetida à experiência infantil de natureza sexual.
\end{abstract}

Palavras-chave: Trauma, temporalidade, sexualidade, metapsicologia, narcisismo 
Um assunto que tem vindo à tona, recentemente, são as conseqüências para o psiquismo humano das situações catastróficas que se têm apresentado ao homem, de forma tanto mais intensa, quanto mais os veículos de comunicação de que dispomos nos apresentam, com a maior e riqueza de detalhes, todos os desastres, guerras, violências e sofrimento humano, que nos tocam como algo da ordem do incompreensível. A ampliação do estudo e a pesquisa sobre as posttraumatic stress disorders (PTSD) nos dá uma boa medida da importância que assume o trauma nas discussões atuais.

Qual a contribuição da psicanálise neste âmbito? A clínica psicanalítica nos confronta incessantemente com as repercussões destes acontecimentos, a angústia oriunda da exposição à violência e da incompreensão ante as grandes desgraças.

Desde os primórdios da constituição da teoria freudiana, o trauma é uma noção central em suas elaborações teóricas.

Deparamo-nos, entretanto, com uma ampla polissemia e mesmo com interpretações conflitantes a que o termo trauma está sujeito dentro do campo da psicanálise. Em 1964, houve um simpósio sobre o tema, cujas contribuições foram editadas por Sidney Furst (1967). A diversidade das abordagens e conceituações do termo trauma, evidenciada no encontro, foi de molde a provocar em Anna Freud (1967) o comentário de que tão vasta amplidão de acepções do termo trauma terminara por ocasionar a perda do seu valor conceitual, já que sua significação se tinha diluído:

... a definição de trauma, que se amplia atualmente desde a noção original de quebra através da barreira de estímulos, em um extremo, até as noções de trauma acumulativo, de esforço, retrospectivo, encobridor, até que se torna difícil no outro extremo, diferenciar entre influências adversas e patogênicas em geral e trauma em particular. (Freud, A., 1967, p. 235)

A ênfase na literatura psicanalítica, no trauma infantil de ordem sexual, não parece contemplar a especificidade das novas sintomatologias com que nos deparamos. Para iniciar uma pesquisa sobre o trauma na conceituação psicanalítica, assim como discutir sua potencialidade para nos permitir abordar as questões emergentes em nossa clínica na 


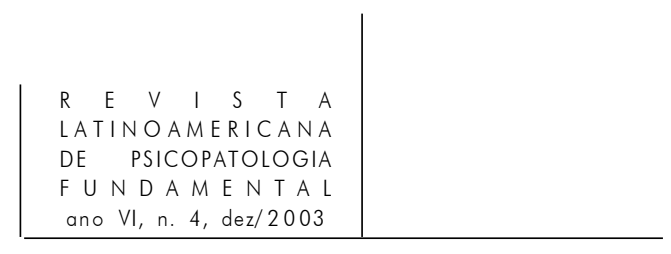

atualidade, uma revisão das formas que assume na metapsicologia freudiana é necessária, embora não se possa desconsiderar a importância das contribuições posteriores ao tema.

Nos primórdios da psicanálise, o trauma como sedução sexual da criança pelo adulto foi tomado como o fator primordial em ação na psicogênese das neuroses. Como se sabe, em 1897 Freud coloca em questão a universalidade das investidas sexuais às crianças por parte de seus pais, e gradativamente passa a promover os desejos edípicos e a fantasia. Muitas discussões têm sido suscitadas por esta virada. Primeiramente, em seus relatos sobre o momento em que "deixou de acreditar em suas neuróticas", é como se elas costumassem relatar seduções sexuais sofridas na infância. Já a leitura dos casos clínicos da época mostra que, na verdade, as seduções supostamente ocorridas, eram, na realidade, por ele inferidas, tanto a partir dos sintomas quanto das associações. Ou seja, jamais foram relatos dos pacientes, e sim construções do próprio Freud. Este é um tornozelo de Aquiles que propiciou ataques recorrentes à psicanálise e ao seu fundador, como os de Cioffi (2000) e Macmillan (1997).

Masson (1984), precursor dos chamados "Freud bashers", por outro lado, baseou suas críticas na idéia de que Freud recuou covardemente de sua primeira teoria, embora estivesse perfeitamente a par de uma vasta documentação, existente na França, sobre a freqüência dos abusos sexuais de crianças, com a qual teria tido contato quando estudava com Charcot. As razões para este recuo teriam sido o constrangimento que esta teoria causou a seus pares, e seu desejo de proteger-se da idéia de ter sofrido ataques sexuais por parte de seu pai.

O abuso sexual de crianças vem, sem dúvida, retomando um lugar de importância na literatura, assim como as discussões a respeito da sedução: será fato ou fantasia?

Este debate a respeito da natureza do trauma - sua realidade é psíquica ou factual? -, embora tome a psicanálise como referência central, geralmente para atacá-la, passa ao largo do significado da noção de realidade psíquica no pensamento freudiano.

A promoção da realidade psíquica como sendo o campo próprio da psicanálise, não significa restringir este campo às fantasias, desconsiderando os fatos. Mesmo nos casos em que não há qualquer dúvida de que ocorreu uma sedução infantil, o elemento de fantasia está presente e não pode ser desconsiderado (Bergmann, 1992). Ao comentar, por exemplo, os efeitos da noção de realidade psíquica sobre o mecanismo dos sintomas histéricos, diz Freud:

Eles não deveriam mais ser considerados derivativos das memórias recalcadas da infância; mas entre os sintomas e as impressões infantis, estavam inseridas as fantasias do paciente (ou memórias imaginárias), geralmente 


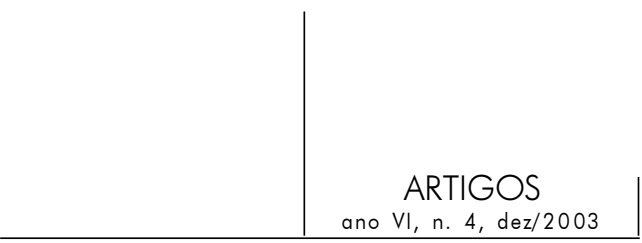

produzidas na puberdade e que, por um lado, foram construídas a partir das memórias da infância e, por outro, transformadas diretamente em sintomas. Só depois da introdução deste elemento das fantasias histéricas, a textura da neurose e sua relação com a vida do paciente tornaram-se inteligíveis. (Freud, 1906, p. 274)

Ao dotar as cenas de sedução, construídas em análise, de realidade psíquica, Freud não as caracterizou como meras fantasias, mas apenas descartou um realismo simplista, como dá a entender em 1917:

Se as experiências infantis desveladas pela análise fossem invariavelmente reais, sentiríamos estar apoiados em solo firme; se fossem regularmente falsificadas e reveladas como invenções, fantasias do paciente, seríamos obrigados a abandonar este chão oscilante e procurar salvação em outro lugar. Mas nenhuma das alternativas é o caso: o que pode ser demonstrado é que as experiências da infância construídas ou lembradas em análise são, às vezes, indiscutivelmente falsas e, às vezes, com a mesma certeza, corretas, e o mais das vezes compostas de verdade e falsidade. (p. 367)

O trauma da sedução sexual pelo adulto, que ocupou a posição de fator etiológico fundamental nas neuroses, embora tenha perdido, a partir de 1897 (Freud, 1897/1950), espaço para a fantasia e a sexualidade infantil, nunca desapareceu da psicanálise. Retorna insistentemente, em novas e mais refinadas versões, como a linguagem da paixão, ferencziana, que irrompe traumaticamente no mundo infantil, até a teoria laplanchiana da sedução generalizada.

É especialmente no sentido de um trauma infantil de natureza sexual que ele têm sido apresentado na literatura. Quando aborda os sintomas neuróticos, a teoria psicanalítica os remonta a um conflito no qual as forças defensivas se erguem contra uma fantasia que é da ordem sexual, pulsional, e conflitiva. Sua realização poderia convocar algo de mal-vindo, como o abandono, a perda do amor, a punição ou castração. Este quadro interpretativo clássico da psicanálise não parece cobrir todas as sintomatologias resultantes dos traumas, especialmente muitas que a clínica nos apresenta atualmente.

A primeira versão do processo primário é a que o caracteriza pela tendência a alucinar o desejado, e a amputar do pensamento as representações que evoquem a dor.

Uma vez que esta versão foi elaborada em um texto de que ficou por muitos anos desconhecido do público por desejo do próprio Freud, tendo sido publicado apenas na década de 1950 (Freud, 1895-1950), a primeira formulação oficial dos processos primários foi a do livro A interpretação dos sonhos (1900), que acompanha, em linhas gerais, a anterior, exceto pelo fato de que a experiência de dor e a tendência a repelir os pensamentos dolorosos, uma das duas tendências que compunham os processos psíquicos primários em 1895, não é mais 


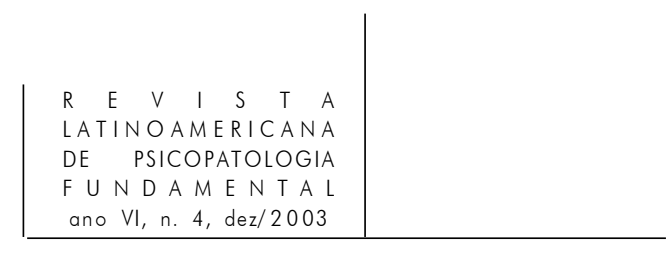

mencionada. Resta a tendência a investir as imagens satisfatórias, descrita em termos semelhantes aos do texto inédito à época, mas que passa a ser, em 1900, a única força a caracterizar os processos psíquicos primários. Oficialmente, portanto, as forças pulsionais, que se constituíram a partir das experiências de ser cuidado e alimentado pelo ser materno, foram apresentadas como hegemônicas no inconsciente, e as experiências de dor deixaram de receber atenção.

Este momento da construção teórica retrata exatamente o que estava sendo descoberto na clínica - a prevalência dos temas sexuais vislumbrados através do discurso e sintomas dos pacientes histéricos. A pesquisa inicial de uma cena traumática até a descoberta do trauma sexual da sedução, e o posterior reconhecimento de que aquilo que o paciente relata sempre envolve as fantasias sexuais, configuram um período da psicanálise em que a questão mais premente da clínica é a sexualidade, e a metapsicologia reflete este momento.

Falta melhor circunscrever o trauma doloroso (chamá-lo de não-sexual é anátema), já que este está se fazendo cada vez mais presente na clínica atual. Esta versão do trauma foi inicialmente imposta a Freud pelos casos de neurose traumática pós-guerra, que resultavam de acidentes dolorosos recentes e, aparentemente, não tinham qualquer relação privilegiada com objetos sexuais. Os sintomas desta afecção, propõe Freud em 1916, resultam de uma fixação no momento do acidente traumático. Este passará a ser reeditado nos sonhos, e ressurgir em ataques histeriformes que transportam repetidamente o sujeito para a situação do trauma, como se fosse impossível superá-la. Às vezes o sintoma é o reviver quase alucinatório do trauma, hoje chamado de flashback.

Estes sintomas embaraçam o fundador da psicanálise, levando-o a confessar que as neuroses traumáticas são diferentes das neuroses espontâneas, com as quais a psicanálise estava à vontade na época: "não tivemos sucesso em integrálas com nossos conhecimentos atuais" (Freud, 1917, p. 274).

Suas reflexões, fruto da perplexidade com que esta nova clínica o confronta, não cessam. Em 1918, apresenta em Budapest, no 5ํㅡㄹ Congresso Internacional de Psicanálise, um artigo publicado no ano seguinte, no qual propõe uma unificação das hipóteses teóricas com que aborda as neuroses de transferência com novas elaborações sobre as neuroses de guerra. Neste texto, Freud (1919) admite, de saída, que a etiologia sexual está ausente das neuroses de guerra, já que estas são desencadeadas por um perigo externo, enquanto nas neuroses de transferência o perigo provém de dentro, ou seja, das próprias pulsões. Aparentemente, o tema era espinhoso para Freud, pois embora reconheça a eficácia de um trauma não sexual na neurose traumática, vai, depois, como veremos, desmentir a si mesmo em 1926.

Para integrar estas observações discordantes dentro de uma rede conceitual coerente, que dê conta tanto das neuroses de transferência e narcísicas como 


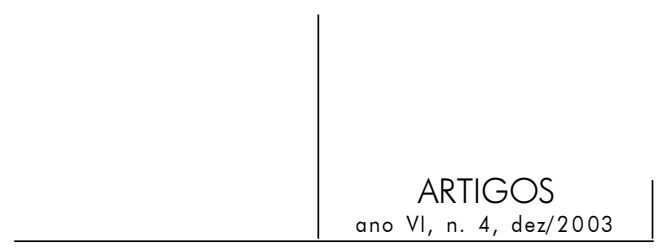

das traumáticas, Freud recorre à ampliação da teoria da libido, efetuada em 1914, com a introdução do conceito de uma libido narcísica. Ensaia apoiar os sintomas da neurose traumática em uma cisão do eu, quando reconhece nos sintomas dos neuróticos de guerra um conflito entre o "antigo ego pacífico" (Freud, 1919, p. 209) do soldado e o novo ego guerreiro exibido pela situação de combate, uma vertente teórica que tem sido explorada por alguns autores, atualmente (Abraham e Torok, 1987).

Embora reconheça que o perigo surge de fora, na guerra, e de dentro, nas neuroses de transferência, Freud busca atenuar a importância desta diferença, acentuando que é sempre a integridade do ego que está ameaçada, tanto no caso da morte física, virtualidade sempre presente na situação de guerra, quanto no caso de uma falência total do ego, equivalente à morte subjetiva, e conclui qualificando o recalque, que fundamenta qualquer neurose, como resultante de trauma, ou seja, "como uma neurose traumática elementar" (Freud, 1919, p. 210). Todavia, quando Freud faz o trauma equivaler ao recalque originário fundador do psiquismo, dá-lhe um lugar estrutural e completamente diferenciado da sintomatologia específica que resulta de um trauma atual: a repetição inesgotável do acidente que o desencadeou.

Esta tentativa de integração se mostrará insuficiente para preservar a metapsicologia sem grandes modificações. O "valor falsificador" dos sintomas da neurose traumática terminará por determinar a grande reformulação de 1920 , na qual o princípio do prazer perde seu lugar de privilégio como o grande regente do psiquismo, e a repetição ganha um lugar mais fundamental, de instrumento privilegiado pelo qual as experiências traumáticas virão a ser gradativamente integradas aos domínios do princípio do prazer. Mesmo assim, os problemas que nos colocam os sintomas de trauma ainda não mereceram a atenção que deveriam.

\section{Temporalidade e trauma}

A noção de Nachträglichkeit, destacada por Lacan na teoria freudiana, define uma temporalidade própria à formação dos sintomas neuróticos, nos quais as experiências infantis são tomadas como centrais. Minha questão é se ela poderá ser transportada, da mesma forma, para os sintomas de traumas.

Já presente nos primeiros escritos (Freud, 1895), a noção de Nachträglichkeit significava o movimento pelo qual uma memória só adquiria a qualidade de traumática bem após o acontecimento. A sedução infantil não teria efeitos imediatos, mas só com a puberdade e com o advento da sexualidade viria a adquirir um sentido sexual precipitando o recalque. O pressuposto desta teoria é que a maturação, fator de ordem biológica, se encarregaria de introduzir a 


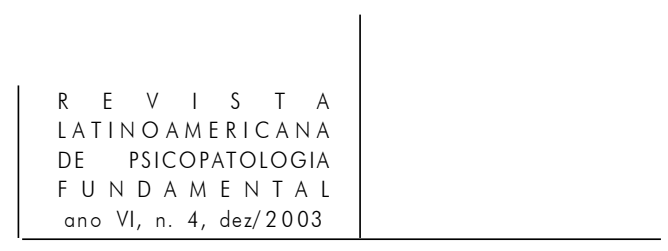

sexualidade na vida do púbere, com o que a memória seria dotada de uma significação sexual antes inexistente.

A contribuição de Lacan ao alertar para o valor da noção foi valiosa, já que a tradução para o inglês - deferred action - não foi mantida de forma coerente, mas o termo alemão foi traduzido de formas diversas nos vários contextos e artigos. Esta oscilação de tradução obscureceu o fato de que, no original da obra freudiana, o termo Nachträglichkeit aparece com grande freqüência e de forma consistente o suficiente para que ficasse caracterizado o valor conceitual que Freud lhe atribuía, inapreensível para o leitor das traduções.

Para Laplanche e Pontalis (1967), deferred action não é uma boa tradução para Nachträglichkeit, porque sugere que o evento passado exerce seu efeito causal a partir de um adiamento temporal, interpretação da qual discordam. Consideram que o que se dá é uma determinação retroativa do presente sobre o passado. A idéia de temporalidade introduzida com este conceito, sem dúvida, representa uma concepção de causalidade diversa da concepção tradicional: de uma ação linear do passado sobre o presente.

Entretanto, não há que atribuir qualquer direção a este movimento causal, seja ele progressivo ou retroativo. A temporalidade em questão, no Brasil, traduzida como "só depois" ou a posteriori, situa os sintomas e outras formações do inconsciente como produções que se dão na interseção entre presente e passado, como cristalizações em que as experiências recentes e infantis se encontram a partir de alguma analogia ou ponte.

Este esquema temporal formulado na teoria da sedução traumática, resistiu à virada da fantasia e da sexualidade infantil, continuando a vigorar depois do abandono da teoria da sedução e do método catártico. Recebe especial atenção na análise do Homem dos lobos, em que a cena primária, de ordem traumática, não pode ser lembrada, mas é construída em minúcias pelo analista a partir do sonho dos lobos. Além do mais, seu valor de determinação independe de se ela realmente foi vista, ou se foi construída pelo menino ao observar o coito de animais.

Lacan (1986), em seminário de 19/5/1954, valoriza o momento do acontecimento como uma cunhagem, em um inconsciente não recalcado, de uma cena não dotada de significação, limitada ao domínio imaginário. Quando o menino entra no mundo simbólico, o que foi cunhado sofrerá uma transformação. O trauma, que só intervém a posteriori, é recalcado como núcleo do inconsciente. Este recalcado não será mais integrado ao mundo simbólico do sujeito, mas continuará a falar através de seus sintomas.

Geralmente, Lacan concebe o trauma como a própria entrada do infante no novo meio da linguagem, lendo de maneira própria o trauma do nascimento de Rank. Aqui o trauma não comparece como algo determinado por fatos contingentes, mas como momento inevitável da própria constituição do psiquismo. 


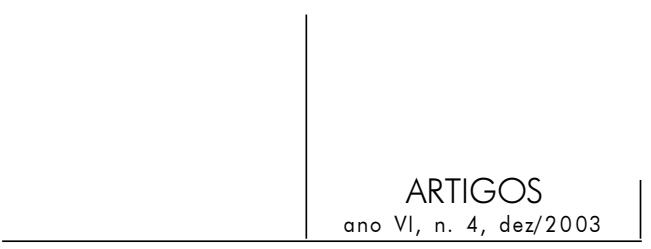

Nesta acepção, mais estrutural, o trauma não pode justificar alguma predisposição que distinga certos sujeitos, como "vulneráveis" ao adoecimento. ${ }^{1}$

Neste mesmo âmbito estrutural, Freud (1923a) retorna a esta temporalidade ao afirmar que as ameaças de castração só são dotadas de seu valor traumático a posteriori, quando o menino se depara, pela primeira vez, com o genital feminino, ou melhor, com o sinal de menos, que é como pode apreendê-lo inicialmente. Pode então representar a possibilidade de perda do próprio pênis.

A temporalidade Nachträglichkeit não tem seu âmbito restrito ao momento do recalque primário, e é correlativa da importância da experiência infantil na obra freudiana. $\mathrm{O}$ acontecimento recente se reforça com a energia latente do recalcado, enquanto este só consegue agir através do recente, o que mantêm vivas os rastros, no psiquismo adulto, das experiências infantis. A experiência analítica, para Freud, convence a todos da verdade de que "a criança é pai do adulto" (Freud, 1938, p. 187), tal a importância dos primeiros anos de vida.

A sintomatologia da neurose traumática, entretanto, não parece tão fortemente determinada pelas experiências da infância. A própria morfologia dos sintomas é bastante específica, uma mera repetição da experiência traumática recente, seja em sonhos, em recordações, em flashbacks, ou mesmo em repetições ativas. Estão ausentes as relações simbólicas com uma fantasia de desejo, como nos sintomas nas neuroses de transferência.

É claro que ao chamar a atenção de que os sintomas traumáticos têm uma relação com o infantil diferente da que vigora nas neuroses de transferência, não se desconsidera que não se pode prescindir de um solo constituído no passado como condição de possibilidade para o surgimento dos sintomas. O trauma não pode ser caracterizado exclusivamente pelo acontecimento. Entretanto, indubitavelmente, as experiências inassimiláveis atuais são as mais importantes na determinação dos sintomas.

A Primeira Guerra Mundial e seus traumatizados introduziram na teoria psicanalítica, como vimos, a necessidade de uma reformulação que será efetivada em "Além do princípio do prazer" (Freud, 1920). Entretanto, a resistência a levar a sério as novidades que as neuroses traumáticas demandam para os teóricos da psicanálise não é pequena. Em prol da desejada unificação teórica, como vimos, no próprio Freud, o trauma na origem das neuroses de guerra é forçado a se tornar cada vez mais próximo de um trauma infantil, até a conclusão de que "temos todo o direito de descrever o recalque que está na base de toda neurose, como uma reação a um trauma - como uma neurose traumática elementar" (1919,

1. É importante esta noção de vulnerabilidade ao trauma para toda uma corrente de autores, da qual faz parte McDougall (1991), que considera que um evento catrastófico atual só se provará traumático e gerará sintomas, se reativar um trauma primitivo. 


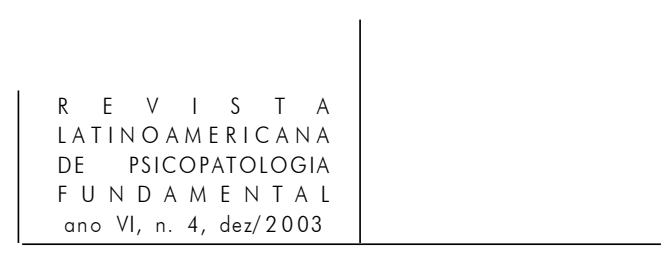

p. 210). Entretanto, este trauma elementar de valor estrutural, como vimos, nada explica da sintomatologia da neurose traumática. Permanece sem resposta a questão levantada pela sintomatologia diferente das neuroses espontâneas e traumáticas.

O ruído provocado pelos sintomas da Primeira Guerra Mundial, na teoria psicanalítica, reproduz-se, em grau ainda maior, a partir da Segunda Guerra. A partir daí, como observa Rapapport (1968), quando a literatura psicanalítica se volta para a neurose traumática, é para negar sua existência. Trata-se de um paradoxo que intriga: que, depois de um período de tão grandes catástrofes, nos quais os sintomas produzidos por um violento trauma social como foi o regime nazista, adquiriram tamanha visibilidade, a reação dos psicanalistas tenha sido a de negar a existência da neurose traumática.

O fato é que a maioria dos autores psicanalistas defendia que não há uma neurose específica produzida exclusivamente pela situação de guerra, ou seja, uma neurose traumática. $\mathrm{O}$ que se via eram neuroses como quaisquer outras, com a única diferença que o fator desencadeante fora especialmente severo. Entre estes autores, Rapapport (1968) cita Fairbairn, Kardiner e Brenner.

Com isto, a ênfase é retirada de condições atuais tão adversas que dificilmente poderiam ser suportadas, pela maioria das pessoas, sem adoecimento psíquico, e dirigida para os conflitos infantis ou vulnerabilidades forjadas por uma infância pouco favorecida em termos de relações com os adultos cuidadores. Surpreendentemente, até Bettelheim (1943) apoiou esta posição, tomando os sintomas pelos quais foi acometido depois de ter estado por um ano como prisioneiro nos campos de concentração de Dachau e Buchenwald, como indicadores de que sua análise havia sido incompleta.

Os psicanalistas relutam em renunciar à idéia de que uma boa mãe, ou, na falta dela, uma boa análise, poderiam garantir a saúde psíquica, independente dos percalços com que a vida pode confrontar as pessoas. Em sintonia com isto, ao lerem "Análise terminável e interminável”, prestam bem maior atenção à barreira da castração como um limite para o alcance da psicanálise, que nem mesmo é caracterizado por Freud como inexpugnável, do que ao lúcido argumento freudiano de que o tratamento psicanalítico não pode garantir a prevenção de adoecimentos pela simples razão de que ninguém sabe o que vida apresentará a cada um.

As neuroses resultantes de catástrofes sociais se apoiariam, na verdade, sobre um trauma da infância, e esta vulnerabilidade prévia é que, no fundo, os determinaria. A relutância em admitir a vulnerabilidade a acontecimentos desorganizadores, se expressa na atribuição à psicanálise da possibilidade de nos imunizar contra o adoecimento psíquico. 


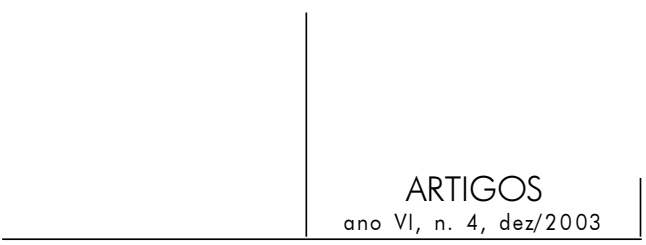

A psicopatologia traumática teve o poder de instalar uma controvérsia no campo da psicanálise. Grande parte dos analistas enfatiza a infância e a relação com a mãe como o terreno onde se instala uma vulnerabilidade, considerando o trauma atual apenas uma reativação do trauma infantil. Outra corrente considera que eventos catastróficos podem dar origem a psicopatologias, independente de predisposições oriundas da infância.

A experiência infantil é, para a psicanálise, estruturante do psiquismo; como tal, seguramente terá efeitos na forma como se reagirá a eventos traumáticos posteriores. Mas isto não dá conta do sintoma traumático. Assim, para Phillips (1991, p. 148), "a nova experiência precisa em parte ser compreendida a partir da natureza do evento traumático". Sem levar em conta o evento, não se poderia compreender um trauma de massa, como os que se manifestam após as grandes catástrofes.

\section{Trauma e desamparo}

Na segunda tópica, qual o lugar do trauma? O papel dado, na nova teoria da angústia, a Hilflosigkeit, o desamparo humano, é o de definir a experiência traumática como estruturante do psiquismo e fundamento do laço social. Sabemos a história oficial: na primeira teoria, a angústia era conseqüência do recalque. Era, portanto, transformação e descarga da libido sexual que, por obra do recalque, ficara impedida de buscar satisfação. $\mathrm{Na}$ segunda teoria, que entretanto não invalida a primeira, mas a inclui em um todo mais complexo, invertem-se esses termos: é a angústia que determina o recalque.

A angústia como transformação da libido era obviamente de origem sexual. Mas a partir de 1926 ela adquire um papel autônomo no psiquismo. Ao ressaltar o papel do desamparo infantil, Freud toma a prematuridade do infante, sua incapacidade de conseguir por si mesmo os objetos de que necessita para sua sobrevivência, e de assim se livrar do desconforto, da dor e da morte, como um solo biológico que é pré-condição para o intenso desejo de proteção e amor que habita o ser humano.

Todas as situações traumáticas estarão referidas ao desamparo. Não se deve esquecer, entretanto, que o termo Hilflosigkeit, que tem suas condições biológicas na precariedade do equipamento adaptativo do homem ao nascer, não designa esta configuração de ordem biológica, mas corresponde à situação infantil do desamparo captada subjetivamente como necessidade de uma ajuda externa (Bleichmar, 1988, p. 63). O laço com o adulto e o amor se estabelecem como condições fundamentais para a estabilidade psíquica. 


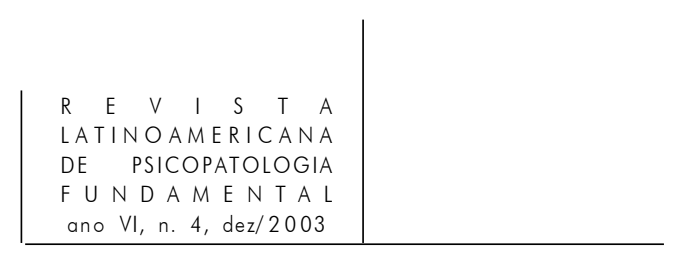

As situações traumáticas serão sempre relativas a situações de separações e perdas, de partes de si, da mãe, de seu amor, do amor do supereu. É curioso que, como observa Bose (1995), a literatura sobre as depressões e perdas refirase tão pouco ao conceito de trauma. A história da humanidade é povoada de traumas coletivos, envolvendo perdas que afetam um grande número de pessoas.

A situação que o infante considera perigosa e contra a qual deseja ser salvaguardado é aquela de não satisfação de uma crescente tensão devido à necessidade frente à qual é impotente (Freud, 1926, p. 137), e o adulto e seu amor lhe garantem proteção. Não se trata, inicialmente, de solicitar o adulto como um objeto sexual, mas, face ao sofrimento, buscar os cuidados que ele pode oferecer. $\mathrm{O}$ amor do adulto é o que protege a criança da inundação por estímulos internos e externos, e a falta deste amor levará ao desamparo. A concepção da angústia traumática como originária de um acosso pelas pulsões indomadas e insatisfeitas não pode mais aspirar a uma posição exclusiva, já que nem todas as situações de perigo são de origem pulsional.

A situação traumática e a situação de perigo se distinguem na medida em que o eu aprende a tomar a angústia como um sinal. A angústia que, originalmente, foi automaticamente deslanchada na situação de desamparo, será depois reproduzida de forma mitigada, como sinal de perigo, graças ao que o ego passa, tal como a criança em suas brincadeiras, da passividade para a atividade, buscando dominar psiquicamente as impressões (Freud, 1926, p. 166-7).

Clifford Yorke (1986) destaca que a angústia traumática é experimentada por todas as crianças quando suas necessidades não são atendidas, e não pode ser equacionada a uma experiência traumatizante da vida adulta. Isto porque, quando contrabalançada por gratificações, faz parte das experiências que estruturam o psiquismo.

Ao apresentar sua nova teoria da angústia, Freud volta-se contra aqueles que tomaram as neuroses traumáticas para contradizer o valor etiológico da sexualidade e alegaram que estas neuroses envolviam apenas a pulsão de autoconservação. $\mathrm{O}$ fundador da psicanálise parece ter esquecido que ele mesmo já observara que a sexualidade não tem papel etiológico nas neuroses de guerra. Seu argumento agora é que a concepção do narcisismo, ao colocar a constituição e a preservação do eu na dependência de um investimento libidinoso, tanto dos objetos amados quanto do próprio sujeito, permite estabelecer os laços das neuroses traumáticas com a sexualidade. Além do mais, o medo da morte não tem outro registro senão o das separações que foram representadas ao longo da vida: perdas e separações do peito, das fezes, do amor. Assim, a angústia da morte é, no fundo, angústia de castração, especialmente angústia de perda do amor do supereu, que parece, nos momentos difíceis, ter nos abandonado aos desmazelos do destino. 


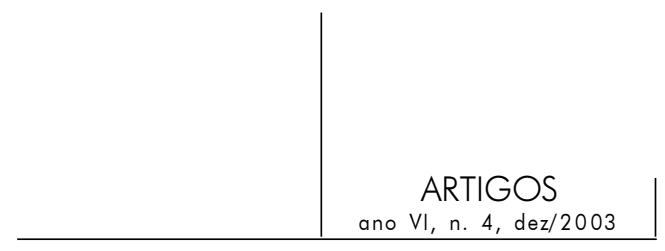

A noção de narcisismo efetivamente possibilita elaborar um laço entre neurose traumática e espontânea; entretanto, ainda assim, a sexualidade toma parte em cada uma delas em condições diversas. Na neurose traumática, a sexualidade participará na tentativa de elaboração de uma resposta possível ao trauma, o acontecimento inesperado e sem sentido, e não como constituindo o próprio acontecimento traumático. $\mathrm{O}$ investimento libidinal no eu é necessário à saúde psíquica.

Tomando o trauma como uma injúria narcísica, pela qual a vítima é roubada do sentimento de continuidade e de reconhecimento de si mesmo e de seu mundo, como propõem muitos autores (Ulman e Brother, 1988), é necessário não considerarmos o narcisismo uma fase ultrapassada, bem ou mal resolvida. A estrutura narcísica é permanente, e a preservação do eu depende não só do investimento amoroso tanto do sujeito como das pessoas que o cercam, como de um meio no qual possa reconhecer um lugar para si mesmo. As situações de catástrofe, em que a integridade corporal do indivíduo e/ou de sua vida é destroçada, equivalem subjetivamente ao abandono pelas figuras protetoras introjetadas, o supereu do amor.

A falta de recursos para lidar com certos acontecimentos jamais é inteiramente superada. Pode-se ser reconduzido a uma situação de desamparo em qualquer momento da vida, e não apenas como conseqüência do acosso pelas pulsões insatisfeitas, mas também dos golpes dolorosos do destino, doenças, perdas, violências e traições a que estamos sempre sujeitos, e que muitas vezes significam um grave golpe no narcisismo.

Os recursos simbólicos de que dispomos para lidar com o que a vida pode nos apresentar não são ilimitados. O vazio de razões, a falta de preparação, a impossibilidade de dar qualquer sentido para um acontecimento doloroso, nos remetem a uma posição de impotência para responder a ele e o caracterizam como traumático.

O sinal de angústia possibilita a antecipação e a fuga do estabelecimento de uma situação traumática. Permite pensar no que é doloroso, o que constitui um passo bastante misterioso, já que o sinal de angústia é angústia, e o psiquismo dela foge. Um fato que se apresenta na clínica de todos os psicanalistas, é as associações do analisando lhes revelarem com toda a clareza os indícios de uma situação de perigo a que este está exposto, e que nos comunica, sem saber disto e nem tirar as conseqüências devidas.

O sentido de realidade opera em flagrante oposição à tendência para a fuga da dor. Os julgamentos que permitem antecipar o futuro com acuidade dependem de uma inibição e de uma relativa tolerância ao afeto angustiante, que é essencial ao reconhecimento da realidade. Levando em conta que o critério do prazer determina o acesso de nossas idéias à consciência, Tausk (1924) se pergunta quais são as formas de compensação narcísica que nos permitem suspender o 


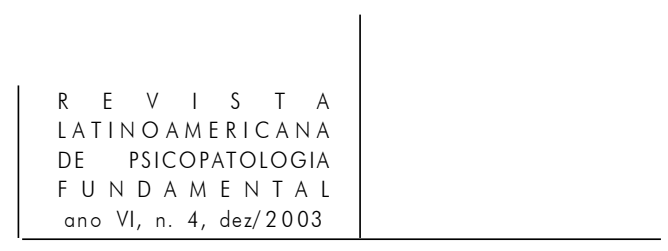

recalque e pensar naquilo que mobiliza a angústia. Já Ferenczi (1926), embora considere que a renúncia ao prazer exigida para reconhecer o que é doloroso é sempre precária, acredita que, assim como há perdas irreparáveis de órgãos do corpo, também no psiquismo pode haver renúncia sem compensações. Só a pulsão de morte, o retorno ao masoquismo, pode dar conta desta possibilidade de contrariar o princípio do prazer e pensar no que causa angústia. Os traços mnêmicos são como cicatrizes de impressões traumáticas e produtos da pulsão destrutiva, mas a ação de Eros permite que sejam usados para formulação de juízos mais lúcidos sobre a realidade que contribuem para a preservação do eu.

A abertura para o trauma é uma virtualidade permanente, mas ele não se constitui "só depois" como uma nodulação entre o recalcado e o acontecimento atual. Como impossibilidade de fazer sentido daquilo que irrompe agora, o trauma não se apóia no recalcado, mas sinaliza um vazio. É porque não há preparação, é porque a angústia não pôde sinalizar nada, que a barreira foi rompida, e a angústia automática se instalou (Freud, 1926, p. 162), estabelecendo-se o estado traumático. A compulsão à repetição busca, retroativamente, dominar o estímulo excessivo e gerar um sinal que nos proteja contra ser novamente apanhado desprevenido pelo evento traumático. Este é um trabalho de elaboração que visa construir algo onde não havia nada. Não há, portanto, uma temporalidade Nachträglichkeit, na gênese de uma psicopatologia traumática. Isto se manifesta com clareza na literalidade que caracteriza o sintoma traumático, assim como na resistência à representação do trauma por metáforas (Seligmann-Silva, 2000).

É este vazio que não permite caracterizar teoricamente o trauma apenas pelas qualidades do acontecimento que surpreendeu dolorosamente o sujeito. O valor traumático do acontecimento é relativo a um determinado psiquismo, e, portanto, regido não apenas pelas qualidades do fato, mas também pela história do sujeito. O que a história justifica é a impossibilidade de antecipar ou de integrar um evento, como algo dotado de uma significação que possa se articular às narrativas que o sujeito se dá de si mesmo e do mundo em que vive. Por isto mesmo, o sintoma assume a feição de uma interminável repetição, em que a tentativa de integrar o corpo estranho que é o acontecimento traumático vivido, à própria história, é o móvel dominante.

\section{Referências}

Abraham, N. e Torok, M. (1987). A casca e o núcleo. São Paulo: Escuta, 1995.

Bergmann, M. An infantile trauma, a trauma during analysis, and their psychic connexion. The Int. Journal of Psycho-Analysis, London, v. 73, p. 447-54, 1992. 


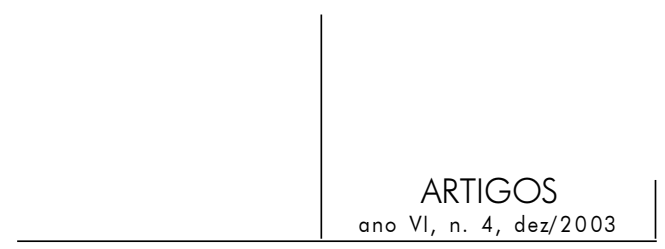

BetTelheim, B. Individual and mass behavior in extreme situations. Journal of Abnormal Psychology, v. 38, p. 417-52, 1943.

Bleichmar, H. Angústia e fantasma. Porto Alegre: Artes Médicas, 1988.

Bose, J. Trauma, depression, and mourning. Contemporary Psychoanalysis. New York: v. 3, p. 399-407, 1995.

Ciofri, F. (1998). A controvérsia freudiana: o que está em questão? In: Roth, M. Freud conflito e cultura. Rio de Janeiro: Jorge Zahar, 2000.

FERENCZI, S. The problem of acceptance of unpleasant ideas: advances in knowledge of the sense of reality. The Int. Journal of Psycho-Analysis 7, p. 312-23, 1926.

Freud, A. Comments on trauma. In: Furst, S. S. (ed). Psychic Trauma. New York: Basic Books, 1967, p. 235-45.

FReud, S. (1900). The Interpretation of Dreams. SE. London: Hogarth Press, 1975. v. 4, 5. (1906). My views on the part played by sexuality in the aetiology of the neuroses. SE. Op. cit. v. 7, p. 269, 274, 279.

(1914). On narcissism: an introduction. SE. Op. cit. v. 14, p. 67-104.

(1917). Introductory lectures on psycho-analysis. SE. Op. cit. v. 16, p. 243-448. (1919). Introduction to psycho-analysis and the war neuroses. SE. Op. cit. v.

17 , p. 205-10.

(1920). Beyond the pleasure principle. SE. Op. cit. v. 18, p. 3-144.

(1923). The ego and the id. SE. Op. cit. v. 19, p. 3-68.

(1923a). The infantile genital organization. SE. Op. cit. v. 19, p. 141-8.

(1926). Inhibitions, symptoms and anxiety. SE. Op. cit. v. 20, p. 77-175.

(1937). Analysis terminable and interminable. SE. Op. cit. v. 23, p. 3-140.

(1939). Moses and monotheism: three essays. SE. Op. cit. v. 23, p. 3-140

(1940 [1938]). An outline of psychoanalysis. SE. Op. cit. v. 23, p. 141-208.

(1950[1897]). Letter 69. SE. Op. cit. v. 1, p. 259-60.

(1950[1895]). Project for a scientific psychology. SE. Op. cit. v. 1, p. 283-397.

Furst, S. S. (ed). Psychic Trauma. New York: Basic Books, 1967.

LaCAn, J. Os escritos técnicos de Freud. Rio de Janeiro: Jorge Zahar, 1986.

Laplanche, J. \& Pontalis, J.-B. Vocabulaire de la psychanalyse. Paris: PUF, 1967.

Macmillan, M. Freud evaluated: the completed arc. Cambridge, London: The MIT Press, 1997.

Masson, J. M. (1984). The Assault on Truth - Freud's supression of the seduction theory. New York: Pocket Books, 1998.

McDougall, J. Sexual identity, trauma, and creativity. Psychoanalytic Inquiry. Hillsdale, NJ: The Analytic Press, v. 11, p. 559-81, 1991.

RAPPAPORT, E. Beyond traumatic neurosis - A psychoanalytic study of late reactions to the concentration camp trauma. The Int. Journal of Psycho-Analysis. London: v. 49, p. 719-31, 1968.

Seligmann-Silva, M. A história como trauma. In: Nestrovski, A. e Seligmann-Silva, M. (Org.). Catástrofe e representação. São Paulo: Escuta, 2000. 


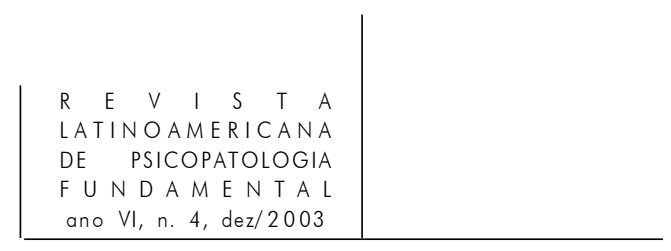

TAusk, V. Compensation as a means of discounting the motive of repression. The Int. Journal of Psycho-Analysis, London, v. 5, p. 130-40, 1924.

Ulman, R. B. \& Brother, D. The shattered self. Hillsdale, NJ: The Analytic Press, 1988.

Yorke, C. (1986). Reflections on the problem of psychic trauma. The Psychoanalytic Study of the Child, v. 41, p. 221-36, 1986.

\section{Resumos}

El trauma ha sido estudiado en la literatura psicoanalítica especialmente como trauma infantil de naturaleza sexual. La neurosis traumática es tomada como modelo para la delimitación de la acepción del trauma que no se confunde con el trauma estructural eficaz en la constitución del psiquismo y cuya sintomatología no puede ser directamente remitida a la experiencia infantil de naturaleza sexual.

Palabras claves: Trauma, temporalidad, sexualidad, metapsicología, narcisismo

Le trauma a souvent été abordé en littérature psychanalytique comme un trauma infantile de nature sexuelle. La névrose traumatique est prise comme modèle pour la délimitation d'une acception du trauma qui ne peut être confondue avec le trauma structurel, efficace dans la constitution du psychisme, et dont la symptomatologie ne peut être directement attribuée à l'expérience infantile de nature sexuelle.

Mots clés: Trauma, temporalité, sexualité, métapsychologie, narcissisme

Traumas have been studied in psychoanalytic literature especially as early traumas of a sexual nature. The traumatic neuroses are taken as a model for delimiting a notion of trauma that should not be confused with the structural trauma present in the constitution of the psychism, as the latter's symptoms cannot be directly attributed to infantile experiences of a sexual nature.

Key words: Trauma, temporality, sexuality, metapsychology, narcissism 